\title{
Febrile Convulsions in Infants at the Pediatrics University Hospital Center Charles de Gaulle of Ouagadougou (Burkina Faso)
}

\author{
A. Kaboré*, A. Diallo, H. Savadogo, S. A. P. Ouédraogo, K. Nagalo, S. Yougbaré, D. Yé \\ Service of Médical Pediatrics, Charles De Gaulle Pediatric University Teaching Hospital, Ouagadougou, Burkina Faso \\ Email: *sita_kab@yahoo.fr
}

How to cite this paper: Kaboré, A., Diallo, A., Savadogo, H., Ouédraogo, S.A.P., Nagalo, K., Yougbaré, S. and Yé, D. (2018) Febrile Convulsions in Infants at the Pediatrics University Hospital Center Charles de Gaulle of Ouagadougou (Burkina Faso). Open Journal of Pediatrics, 8, 199-206. https://doi.org/10.4236/ojped.2018.82022

Received: April 26, 2018

Accepted: June 25, 2018

Published: June 28, 2018

Copyright $\odot 2018$ by authors and Scientific Research Publishing Inc. This work is licensed under the Creative Commons Attribution International License (CC BY 4.0).

http://creativecommons.org/licenses/by/4.0/

cc) (i) Open Access

\begin{abstract}
Context: Seizures rank high among the commonest emergencies encountered in Pediatrics. As far as the etiologies are concerned, the most frequently confronted cause is infectious diseases. Therefore, particularly in the present work context, febrile seizures have been inadequately investigated. The study aimed at assessing the prevalence of febrile convulsions in our pediatrics department. Materials and Methods: This retrospective study was performed in the Pediatrics Medical Service Department of the Pediatrics University Hospital Charles de Gaulle of Ouagadougou in Burkina Faso (West Africa). Infants from one and thirty months of age, hospitalized between January 1, 2011 and December 31, 2012, were included in this study. Seizures are defined as those who accompany fevers above or equal to $38^{\circ} \mathrm{C}$. However, the exclusions from the study included those infants recognized as epileptics; those with abnormal psychomotor development; those afflicted with encephalitis and meningitis; and children with hypoglycemia or dehydration with ionic disorders, as well as those infants who lacked lumbar puncture results. Data were analyzed using the Epi Info software version 3.5.1. Results: While the average age of the patients was 13 months, the average incidence of the febrile seizures was $2.5 \%$. The seizures occurred all through the year, peaking in October (14.1\%). The peak frequency (38.7\%) was recorded in children from 12 to 24 months. About one-half of the patients $(46.2 \%)$ registered a temperature from $38.5^{\circ} \mathrm{C}$ to $39.4^{\circ} \mathrm{C}$. In $68.9 \%$ of the cases, the tonic convulsions were of the common type of convulsions. The number of convulsions was in the range of $>2$ episodes $/ 24 \mathrm{~h}$ in $83.3 \%$ of the children. The pathologies commonly associated with tonic convulsions included acute gastroenteritis (29.4\%), malaria (25.8\%) and bronchopneumopathies (23.3\%). The evolution was favorable in $95.3 \%$ of the cases. Conclusion: While this study confirms the benign character of the febrile convulsions, their recurrent quality necessitates the codification of a
\end{abstract}


prospective study, for clearer identification and closer case monitoring.

\section{Keywords}

Febrile Seizures, Infants, Associated Pathologies

\section{Introduction}

In fact, febrile seizures are epileptic seizures an infant experiences during a febrile episode without intracranial infection [1]. Seizures represent a therapeutic emergency and rank among the most repeated and recurrent neurological issues in Pediatrics [2] [3] [4]. Between 2\% and 5\% of children below 6 years of age are thus affected [5].

In France, one in twenty infants has experienced at least one febrile convulsion prior to reaching 5 years of age [6]. In Africa, studies on the frequency of febrile seizures vary according to the reports from Yaoundé (6.1\%), Nigeria (3.5\%) and the Congo (1.4\%) [2] [3] [7]. Febrile convulsions involve a pathophysiological mechanism [8] that is still under investigation, incorporating a few genetic factors [9] [10] [11], the inflammatory cytokines and cerebral immaturity. However, several authors have recorded their familial and recurrent nature [3] [5].

Based on the post-critical neurological state, two types of febrile seizures are classically distinguished viz., seizure duration and seizure recurrence [5]. The simple febrile convulsions include the generalized seizures, which last less than 15 minutes, and which usually occur just after the patient completes one year of age and is without post-critical deficit. The complex febrile seizures which exceed 15 minutes are frequently partial and recurrent in infants below one year of age and include transient critical post-crisis deficit. The associated pathology, which includes the type of febrile seizure and the early and prompt commencement of the treatment, determines the prognosis.

At the Pediatrics University Hospital Charles de Gaulle (CHUP-CDG), cases of convulsions in infants in the context of fever are well cared for. This study aimed at assessing the prevalence of febrile seizures in this hospital center.

\section{Materials and Methods}

This descriptive retrospective extended between 1 January, 2011 and 31 December, 2012, in the CHUP-CDG's Medical Pediatrics ward. Included in our study were all children aged 1 to 30 months admitted for convulsion and fever but whose exit diagnosis did not include any central nervous system.

However, those infants with known epilepsy, those with abnormal psychomotor development, the cases of encephalitis and meningitis, children with severe hypoglycemia or dehydration with ionic disorders, and all healthy patients as well as those lacking lumbar puncture results were excluded from this study. 
The information required was gathered from the patients' medical data, employing a written record. The focus of this study was on the epidemiological, clinical and evolutionary data. The data were analyzed using the Epi Info software version 3.5.1.

\section{Operational Definition}

We defined cases of febrile seizures in our study as any case received for convulsion + fever greater than or equal to 38 and whose exit diagnosis did not involve any infectious disease of the central nervous system.

\section{Results}

\subsection{Epidemiological Data}

During the term of the study 4154 children between 1 and 30 months were admitted to the Medical Emergency and hospitalized in the Medical Pediatrics ward of CHUP-CDG. Among these patients, 106 experienced febrile seizures, at a frequency of $2.5 \%$. Then fact, $59.3 \%$ of the infants were below one year of age (among which $23.6 \%$ were 6 months old), while $38.7 \%$ of them were 12 to 24 months of age and $2 \%$ were 25 to 30 months old. The patients showed an average age of 13 months. Of the total number of infants, 63 were girls (59.4\%), giving a sex ratio of 0.7 . Indeed, $96.2 \%$ of the children resided in the city, and $71.7 \%$ of the cases had been referred by a peripheral health center. Febrile convulsions were evident right through the year, as indicated in Table 1.

\subsection{Clinical Data}

The characteristics of febrile seizures

In our series, the number of convulsive episodes noted within 24 hours since the illness onset was defined in 30 patients. However, 25 (83.3\%) patients experienced more than two convulsive episodes.

Generalized convulsions (tonic, clonic or tonic-clonic type) occurred in 69\% of the patients, while partial eye revulsion (or eye rolling) was observed in $31 \%$ of the cases. In 47 patients ( $44.3 \%$ of cases) the seizures were followed by a coma.

None of the files contained any information regarding seizure duration or family history of febrile seizures.

Patient temperature on admission was in the range of $38^{\circ} \mathrm{C}$ to $42^{\circ} \mathrm{C}$ with an average of $39.4^{\circ} \mathrm{C}$. In $46.2 \%$ of the cases, the temperature hovered between $38.5^{\circ} \mathrm{C}$ and $39.4^{\circ} \mathrm{C}$.

The pathologies associated with febrile seizures

Several pathologies were linked to febrile seizures in our series, as evident in Table 2.

\subsection{Evolution}

The hospital stay on average was roughly seven days, with the outer minimum 
Table 1. The monthly distribution of the infants with febrile seizures at CHUP-CDG in Ouagadougou, Burkina Faso.

\begin{tabular}{ccc}
\hline Month & Effective (n) & Percentage \\
\hline January & 11 & 10.4 \\
February & 8 & 7.5 \\
March & 14 & 13.2 \\
April & 5 & 4.7 \\
May & 12 & 11.3 \\
June & 8 & 7.5 \\
July & 9 & 8.5 \\
August & 4 & 3.8 \\
September & 5 & 4.7 \\
October & 15 & 14.1 \\
November & 5 & 4.7 \\
December & 10 & 9.4 \\
Total & 106 & 100 \\
\hline
\end{tabular}

Febrile convulsions were evident right through the year.

Table 2. Pathologies associated with febrile seizures in infants at CHUP-CDG in Ouagadougou, Burkina Faso.

\begin{tabular}{|c|c|c|}
\hline Associated pathologies & Effectif (n) & Percentage (\%) \\
\hline Acute febrile gastroenteritis & 48 & 29.4 \\
\hline Severe malaria & 42 & 25.8 \\
\hline Broncho-pneumopathies & 38 & 23.3 \\
\hline Affections ORL ${ }^{*}$ & 9 & 5.5 \\
\hline Urinary tract infections ${ }^{* *}$ & 7 & 4.3 \\
\hline Acute bronchiolitis & 5 & 3.1 \\
\hline Septicemia & 4 & 2.5 \\
\hline Total & $163^{*}$ & 100 \\
\hline
\end{tabular}

ENT disorders: acute laryngitis ( 1 case); Acute pharyngitis ( 6 cases); Acute otitis media: $\left(2\right.$ cases). ${ }^{*}$ Some cases are more than one desease.

and maximum duration being 1 and 23 days, respectively. Of the 101 patients, 95.3\% were cured and 2 expired, implying a death rate of $1.9 \%$. One of these two deaths was due to septicemia, while the other was a pleuropulmonary staphylococcal case. Three patients left against medical advice. These three cases were a life.

\section{Discussion}

\subsection{The Limits of the Study}

Lack in this study was that the absence of a complementary means of investiga- 
tion did not permit some examinations like herpes virus PCR. However, none of this affected the outcomes of our study.

\subsection{Epidemiological Aspects}

The frequency of febrile seizures in our series (2.5\%) bears similarity to the results reported by Eseigbe et al., [3] in Nigeria (2.7\%), and Kaputu et al., in the Congo [2] (1.4\%). This frequency, however, differs from the one recorded by $\mathrm{Ba}$ Dicko et al., in Morocco [12] (11.3\%) and Nguefack et al., in Yaoundé (6.1\%) [3]. A large number of children received for convulsions did not have a CSF examination to eliminate acute meningitis. Their file was therefore excluded. This could explain the low frequency of febrile seizures in our study.

In the prospective studies performed by Nguefack et al., [3] the precise data may have generated more number of cases.

In our series, febrile convulsions were noted to occur right through the year. The most number of cases were registered during January, March, May and October. The January to March period accounted for $31.1 \%$ of the convulsions.

The results of our study concur with those of Kaputu in the Congo [2] who also reported a high number (30.2\%) of febrile seizure cases from December to March.

This discovery is possibly because January to March is the period which corresponds to the season of the harmattan (dry, cold, easterly and dust-laden wind) in our country, favoring the occurrence of respiratory infections and acute febrile gastroenteritis, particularly of the viral variety [13], the pathologies most closely related to the febrile seizures in our series.

October is the month when the incidence of malaria peaks [14] in our study, as well as in the other health facilities across the country, in general. Fever is one of the earliest symptoms of malaria and may be accompanied by seizures, as evident in our series. According to Nguefack et al., [3] in a prospective study on febrile seizures in Yaoundé, $67.7 \%$ of malaria cases were registered. The lack of complementary evaluations (particularly thick blood) in some patients in our study restricted us from considering all the suspected cases of malaria.

Ba Dicko et al. [12] reported a high frequency of seizures (54.62\% febrile) between 12 and 24 months of age (38.7\%), in Morocco.

These findings were possibly due to the fact that between zero and six months of age the maternal antibodies provide immunity to the child thus restricting the sources of infection and thereby of fever. Between 6 and 24 months of age, the child with its immature immune system is more highly exposed and susceptible to infections. Besides, the older the child's brain the less vulnerable it will be to fever [11].

Febrile seizures are a specific age-related entity. Several diverse pathophysiological explanations are presented, referring to age-dependent cerebral hyperexcitability related to fever [9].

An infant below 6 months of age experiencing convulsions with fever requires 
investigation for other etiologies like meningitis, viral meningoencephalitis or early infant myoclonic epilepsy [11]. In their work, Sadarangani et al., [4] reported that in Kenya, seizures with their sources in infections, occurred more frequently (71\%) in children from 1 to 12 months.

\subsection{Clinical Data}

In this study, a large percentage $(71.7 \%)$ of patients was referred from other urban or rural health facilities across the country. Seizures are emergency events that can produce neurological sequelae. Therefore, according to the guidelines of the Integrated Management of Childhood Illness, the health workers refer seizure cases to a specialized center where qualified staff provide the pertinent management.

\subsection{Characteristics of Febrile Seizures}

In our series, the generalized tonic-clonic seizures $(48 \%)$ that were prevalent were also reported by a few other authors [3] [12]. This finding is probably because generalized tonic-clonic seizures are more unmistakably recognizable than the other types of convulsions by the parents, who thus very quickly bring the child in for consultation.

Besides, a strong relationship exists between the intensity of the temperature and the type of convulsion experienced. Patients experiencing relatively low temperature show an inclination to experience partial seizures; on the other hand, a higher temperature would give rise to generalized convulsions [9]. In our study, a high percentage (46.5\%) of patients experienced temperature between $38.5^{\circ} \mathrm{C}$ and $39.5^{\circ} \mathrm{C}$; this would be the reason for the high frequency (69\%) of the generalized seizures.

Although the duration of the seizures is not specified in this study, the high number of convulsions per 24 hours is a factor indicative of poor prognosis.

In this series, due to the lack of data, the febrile convulsions could not be classified as either simple or complex. However, according to most authors, simple febrile convulsions are markedly the commonest [3] [12] [15] [16] and lumbar puncture has no particular bearing on these cases [15].

With respect to temperature, the results of this study correspond to those of Hachimi et al., [16] who reported temperature between $38.5^{\circ} \mathrm{C}$ and $39.4^{\circ} \mathrm{C}$, in Mali. Similarly, Nguefack et al., [3] reported a high average temperature of $39.5^{\circ} \mathrm{C}$ in the Cameroon, although such thermal peaks are not always the trigger factor for seizures. In fact, while these do not always occur at the acme or climax stage of the fever, they can also be observed during the ascent thermal as well as during thermal defervescence [5].

\subsection{Evolution}

In our series, the evolution was proven beneficial, with $95.3 \%$ of the patients being cured through the treatment. Kaputu et al. [2] in the Congo identified a fa- 
vorable evolution in $73.8 \%$ of the cases. This high rate of patient cure in the current study establishes the benign character of the febrile seizures.

\section{Conclusion}

In the present study, febrile seizures were responsible for $2.5 \%$ of the hospitalizations in pediatrics Hospital Center of Charles de Gaulle. This study shows the benign nature of febrile seizures. She recommends us a complete description of the convulsions in the files and especially to push the investigations (lumbar puncture with examination of the CSF) to better establish an etiological diagnosis in case convulsions with fever.

\section{References}

[1] (1993) Guidelines for Epidemiologic Studies on Epilepsy. Commission on Epidemiology and Prognosis. International League against Epilepsy. Epilepsia, 34, 592-596. https://doi.org/10.1111/j.1528-1157.1993.tb00433.x

[2] Kaputu Kalala Malu, C., Mafuta Musalu, E., Dubru, J.-M., Leroy, P., Tomat, A.-M. and Misson, J.-P. (2013) Epidémiologie et caractéristiques des convulsions fébriles de l'enfant. Revue Médicale de Liège, 68, 180-185.

[3] Nguefack, S.,Ngo Kana, C.A., Mah, E., Kuate Tegueu, C., Tchocketeu, P.F. and Mbonda, E. (2010) Aspects cliniques, étiologiques et thérapeutiques des convulsions fébriles. À propos de 325 cas à Yaoundé [Clinical, Etiological, and Therapeutic Aspects of Febrile Convulsions. A Review of 325 Cases in Yaoundé]. Archives de Pédiatrie, 17, 480-485. https://doi.org/10.1016/j.arcped.2010.02.018

[4] Sadarangani, M., Seaton, C., Scott, J.A., Ogutu, B., Edwards, T., Prins, A., et al. (2008) Incidence and Outcome of Convulsive Status Epilepticus in Kenyan Children: A Cohort Study. The Lancet Neurology, 7, 145-150. https://www.thelancet.com/journals/laneur/issue/current

[5] Auvin, S. and Vallée, L. (2009) Connaissances actuelles sur les mécanismes physiopathologiques des convulsions fébriles [Febrile seizures: Current understanding of pathophysiological mechanisms]. Archives de Pédiatrie, 16, 450-456. https://doi.org/10.1016/j.arcped.2009.02.001

[6] Dubé, C.M., Brewster, A.L., Richichi, C., Zha, Q. and Baram, T.Z. (2007) Fever, Febrile Seizures and Epilepsy. Trends in Neurosciences, 30, 490-496.

https://doi.org/10.1016/j.tins.2007.07.006

[7] Eseigbe, E.E., Adama, S.J. and Eseigbe, P. (2012) Febriles Seizures in North Western Nigeria. Nigerian Medical Journal, 53, 140-144.

https://doi.org/10.4103/0300-1652.104383

[8] Nakayama, J., Hamamo, K. and Iwasaki, N. (2000) Significant Evidence for Linkage of Febrile Seizure to Chromosome 5q14-q15. Human Molecular Genetics, 9, 87-91. https://doi.org/10.1093/hmg/9.1.87

[9] Baulac, S., Gourfinkel-An, I., Nabbout, R., Huberfeld, G., Serratosa, J., Leguern, E., et al. (2004) Fever, Genes, and Epilepsy. The Lancet Neurology, 3, 421-430. https://doi.org/10.1016/S1474-4422(04)00808-7

[10] Motte, J. and Vallee, L. (2002) Diagnostic et traitement des convulsions fébriles. Epilepsie, 14, 89-94.

[11] Waruiru, C. and Appleton, R. (2004) Febrile Seizures: An Update. Archives of Disease in Childhood, 89, 751-716. https://doi.org/10.1136/adc.2003.028449 
[12] Ba, D.O. (2006) Convulsions fébriles de l'enfant (Etude rétrospective). Thèse de médecine, Université Hassan II de Casablanca, n 22, 123 p.

[13] Kaboré, A., Zagré, A., Kam, M., Drabo, D., Ouédraogo, R. and Yé, D. (2007) Incidence des diarrhées à rotavirus chez les enfants de 0 à 5 ans hospitalisés à Ouagadougou. Journal de Pédiatrie et de Puériculture, 30, 56-62. https://doi.org/10.1016/j.jpp.2016.11.004

[14] Koueta, F., dao, L., Yé, D., Zoungrana, A., Kaboré, A. and Sawadogo, A. (2007) Facteurs de risque de décès au cours du paludisme grave chez l'enfant au CHUP CDG. Cahiers Santé, 17, 95-99.

[15] Benallal, K., Benaina, S. and Tamert, S. (2014) Convulsions fébriles chez le nourrisson agé de moins d'un an: Causes et indications de la ponction lombaire. 21, 928.

[16] Poma, H.A. (2009) Les convulsions fébriles du nourrisson dans le service de réanimation pédiatrique de l'hôpital Gabriel Touré. Thèse de Médecine, Université de Bamako, n 23, 101 p. 